\title{
Pre-Test CFD Calculations for a Bypass Flow Standard Problem
}

\section{IMECE 2011}

\author{
Richard W. Johnson
}

\section{November 2011}

The INL is a

U.S. Department of Energy

National Laboratory

operated by

Battelle Energy Alliance

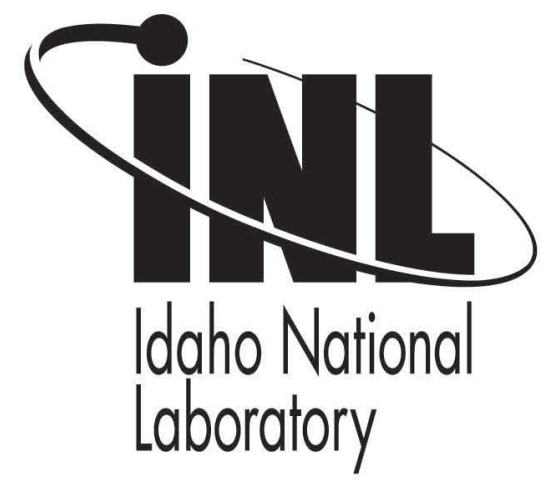

This is a preprint of a paper intended for publication in a journal or proceedings. Since changes may be made before publication, this preprint should not be cited or reproduced without permission of the author. This document was prepared as an account of work sponsored by an agency of the United States Government. Neither the United States Government nor any agency thereof, or any of their employees, makes any warranty, expressed or implied, or assumes any legal liability or responsibility for any third party's use, or the results of such use, of any information, apparatus, product or process disclosed in this report, or represents that its use by such third party would not infringe privately owned rights. The views expressed in this paper are not necessarily those of the United States Government or the sponsoring agency. 


\title{
PRE-TEST CFD CALCULATIONS FOR A BYPASS FLOW STANDARD PROBLEM
}

\author{
Richard W. Johnson \\ Idaho National Laboratory \\ Idaho Falls, Idaho, USA \\ Rich.Johnson@inl.gov
}

Keywords: HTGR, CFD, Bypass Flow, Standard Problem, NGNP

\begin{abstract}
The bypass flow in a prismatic high temperature gas-cooled reactor (HTGR) is the flow that occurs between adjacent graphite blocks. Gaps exist between blocks due to variances in their manufacture and installation and because of the expansion and shrinkage of the blocks from heating and irradiation. Although the temperature of fuel compacts and graphite is sensitive to the presence of bypass flow, there is great uncertainty in the level and effects of the bypass flow. The Next Generation Nuclear Plant (NGNP) program at the Idaho National Laboratory has undertaken to produce experimental data of isothermal bypass flow between three adjacent graphite blocks. These data are intended to provide validation for computational fluid dynamic (CFD) analyses of the bypass flow. Such validation data sets are called Standard Problems in the nuclear safety analysis field. Details of the experimental apparatus as well as several pre-test calculations of the bypass flow are provided. Pre-test calculations are useful in examining the nature of the flow and to see if there are any problems associated with the flow and its measurement. The apparatus is designed to be able to provide three different gap widths in the vertical direction (the direction of the normal coolant flow) and two gap widths in the horizontal direction. It is expected that the vertical bypass flow will range from laminar to transitional to turbulent flow for the different gap widths that will be available.
\end{abstract}

\section{INTRODUCTION}

The U. S. Department of Energy is sponsoring a next generation nuclear plant (NGNP) program to develop an inherently safe fourth generation nuclear reactor design. The program currently is analyzing two basic gas-cooled reactor designs: a pebble bed design where the fuel is encased in tennis ball size pebbles that circulate through the core and a block or prismatic design where the fuel remains stationary in graphite blocks. The prismatic design is based on the General Atomics (GA Tech., 1992) modular high temperature gas-cooled reactor (MHTGR). The MHTGR employs numerous graphite blocks that have been drilled to accommodate fuel pins and channels for coolant flow. The blocks have a hexagonal cross-section and stand about $0.8 \mathrm{~m}$ high. They are designed to stack one on top of another with some reflector blocks above and below the heated blocks. The blocks are arranged in the reactor vessel with inner and outer reflector regions that surround an annular core of fueled blocks. Figure 1 illustrates the cross-section of an MHTGR. The heated blocks are shown in light blue.

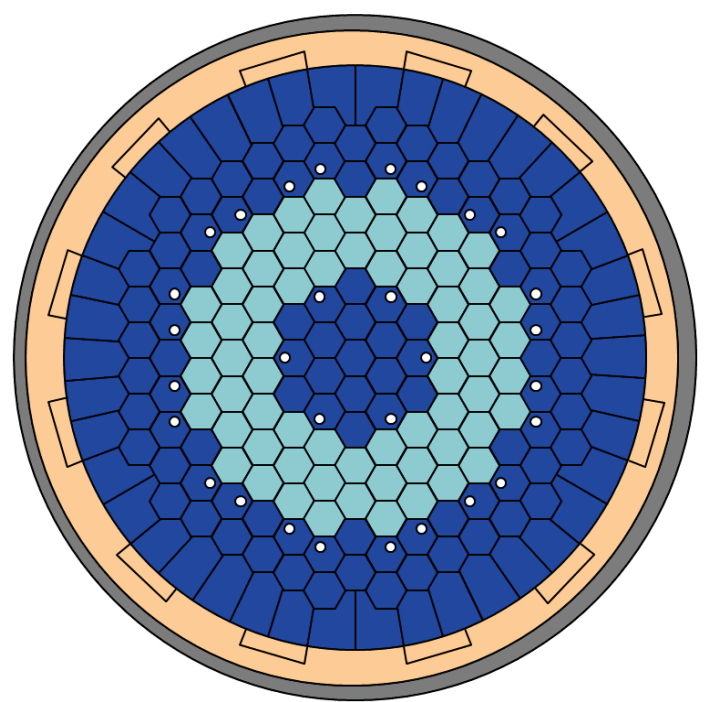

Fig. 1. Cross-section of a GA MHTGR prismatic core.

The blocks are designed to fit together snugly from top to bottom. However, there are vertical gaps between blocks that can vary from a nominal $1 \mathrm{~mm}$ to a few millimeters over the course of time. The spacing varies due to differences in machining, installation and because of volumetric shrinkage and expansion from heating and irradiation. These effects may also affect the snug fit between blocks from top to bottom, leaving horizontal gaps. The gaps between the blocks allow for passage of the helium coolant. Any coolant that does not flow through the drilled coolant channels is considered bypass flow, which 
includes flow in the gaps between blocks. It has been estimated by engineers that as much as $20 \%$ of the flow through the core is bypass flow. This is quite significant, though it has not been clear what effect this has on the core dynamics.

A few detailed studies have been performed to estimate the effects of core bypass flow on a prismatic gas-cooled reactor. Tak et al. (2008) performed a study looking at a symmetric onetwelfth sector of a stack of prismatic core blocks for a VHTR with an outlet temperature of about $1000^{\circ} \mathrm{C}$. However, they obtained inlet flow rates from separate 1-D calculations. Sato et al. (2010) also performed CFD calculations for a one-twelfth sector of a column of prismatic blocks for a $600 \mathrm{MW}_{\text {th }}$ reactor, the initial point design for the NGNP (MacDonald, 2003), which was based on a General Atomics gas turbine modular helium reactor (GT-MHR).

Johnson and Sato (2010) performed new calculations on the current NGNP point design, which is based on the $350 \mathrm{MW}_{\text {th }}$ General Atomics modular high temperature gas reactor (MHTGR), with a nominal outlet temperature of $690^{\circ} \mathrm{C}$. For both of the last two references, flow rates were the result of prescribing nominal pressure drops across the core. These studies estimate that the bypass flow in the vertical gap provides significant cooling to the edge of the block creating a large lateral temperature gradient, increases the maximum fuel and coolant temperatures and greatly increases the difference between the maximum and minimum coolant temperature of the helium coolant as it exits the core.

Sato et al. (2010) and Johnson and Sato (2010) applied partial validation by comparing predicted friction factors in the coolant channels with published correlations. The friction factor is a function of core depth because the Reynolds number decreases with depth (Johnson, 2004). However, the flow in the gap requires further validation because of its complex geometry. An experiment has been designed at the Idaho National Laboratory (INL) to measure isothermal flow in bypass flow gaps to serve as validation data. The present article presents pre-test CFD calculations of the experiment for four configurations. The geometry of the experiment is presented in the next section.

\section{STANDARD PROBLEM GEOMETRY}

The experimental apparatus designed to measure bypass flow in both vertical and horizontal gaps is based on the geometry at the junction of three prismatic blocks. Figure 2 illustrates the junction of three blocks in the prismatic reactor. The experiment geometry is contained within the red outline, which captures the junction of the three blocks, and, hence, three vertical gaps.

Figure 3 provides a close-up view of the junction geometry included in the experimental apparatus. Shown are three coolant channels in each of the three blocks, the vertical bypass gaps, and the presence of bevels machined on the edges of each block. The apparatus is scaled by a factor of 2 larger than the actual block geometry. This allows for larger gap width, making it easier to obtain velocity data using particle image velocimetry (PIV). The apparatus is designed to allow adjustment of the apparatus gap width, from 2 to 6 to $10 \mathrm{~mm}$ (representing 1, 3 and $5 \mathrm{~mm}$ in the true size). The horizontal gap will be adjustable to either 2 or $10 \mathrm{~mm}$ (representing 1 or $5 \mathrm{~mm}$ in the true size).

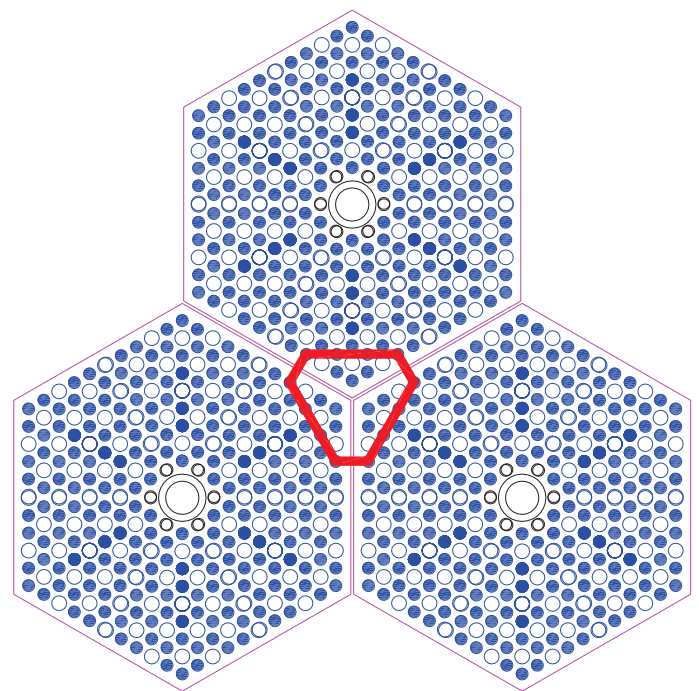

Fig. 2. Three prismatic blocks showing geometry source.

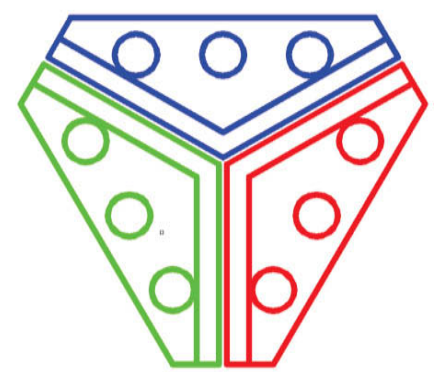

Fig. 3. Close-up view of the bypass experiment geometry.

The apparatus is extended in the vertical dimension to include one full block and a partial second block, which allows the apparatus to fit within the test section of the INL's matched index of refraction (MIR) facility. Figure 4 provides a 3-D view of the bypass apparatus. Shown are the inlet port, upper plenum, two fuel blocks, an adjustable horizontal gap and screens that will be used to produce the same pressure drop across the second block as across the first.

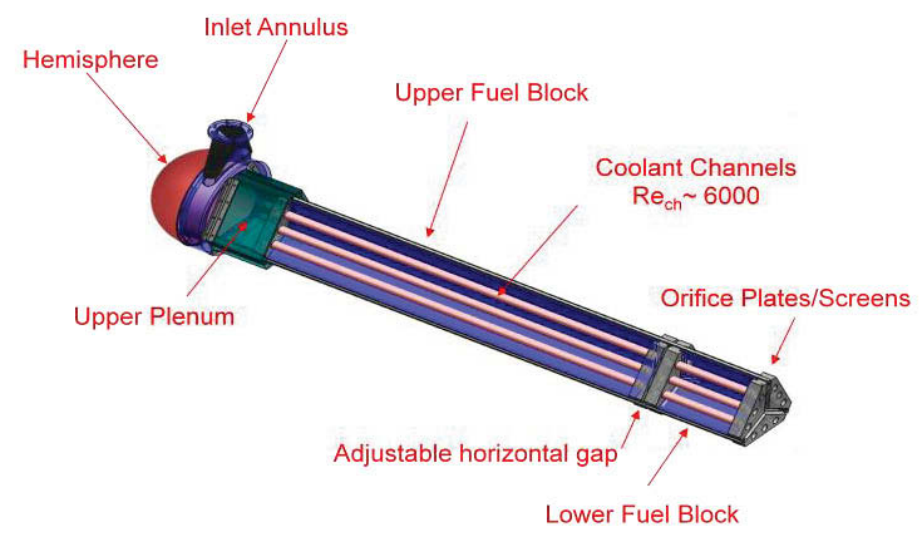

Fig. 4. Isometric view of the bypass apparatus.

The fluid flowing in the apparatus is mineral oil, which at a certain temperature has an index or refraction that matches that of the quartz used to build the apparatus. The oil will flow through the inlet port into an annulus with slots pointed upwards 
and then into the dome where it will be turned 180 degrees back toward the upper plenum. From the upper plenum, the fluid will flow into the three joined gaps and the nine coolant channels. At the end of the first block, the oil from the coolant channels and the bypass gap can comingle again before moving on to the nine channels and bypass gaps in the second block. Finally, the oil will exit the channels and gaps into the test section of the MIR facility where it will circulate around and be cycled back through the bypass apparatus. Velocity and pressure data will be taken in the bypass apparatus using stereo PIV and pressure transducers. The oil flow is related to the actual helium flow through Reynolds number similarity. Measurements will be compared to CFD calculations for validation purposes. The present paper provides pre-test or blind CFD calculations for four gap configurations.

\section{CFD MODEL}

The CFD models used in the present study consist of a onesixth section of the full geometry because of symmetry. Figure 5 shows a top view of the CFD grid, constructed using GAMBIT 2.4.6, which is bundled with CFD code FLUENT (FLUENT 2010). Also shown is the coordinate system; the axial coordinate $\mathrm{Z}$ is negative in the flow direction with zero datum at the inlet. Figure 6 gives an isometric view of the CFD model. Figure 7 shows the transition from the upper plenum to the channels and vertical gap; the bevel can be seen at the beginning of the gap.

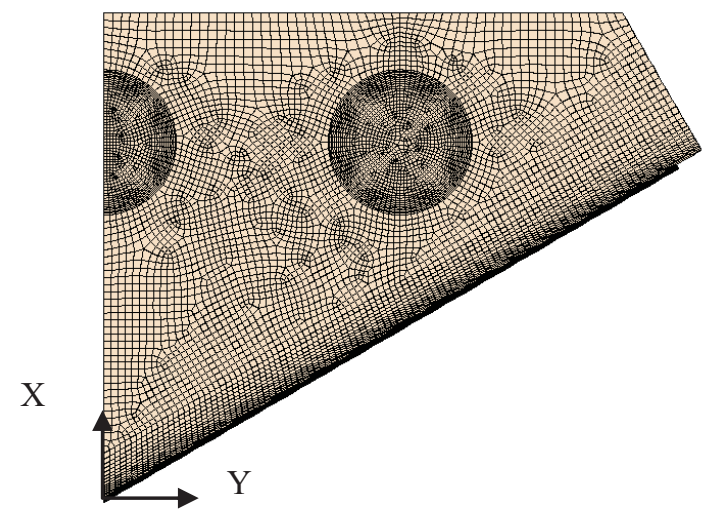

Fig. 5. Top view of CFD model with mesh.

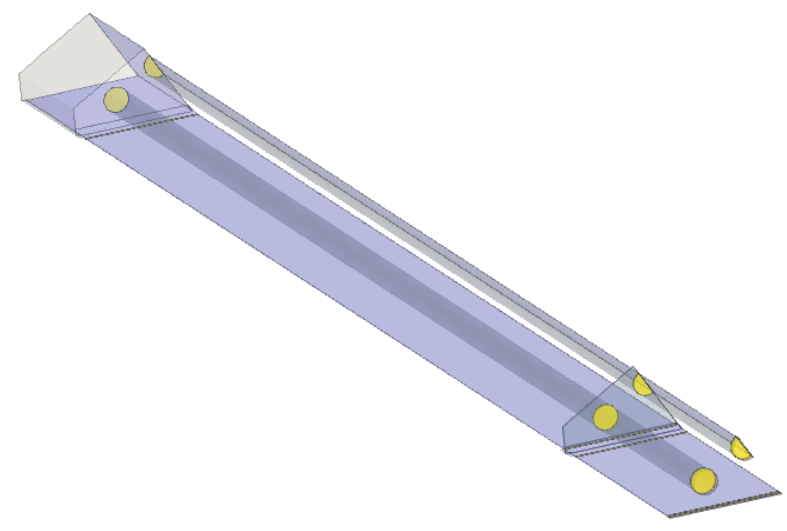

Fig. 6. Isometric view of the CFD model.

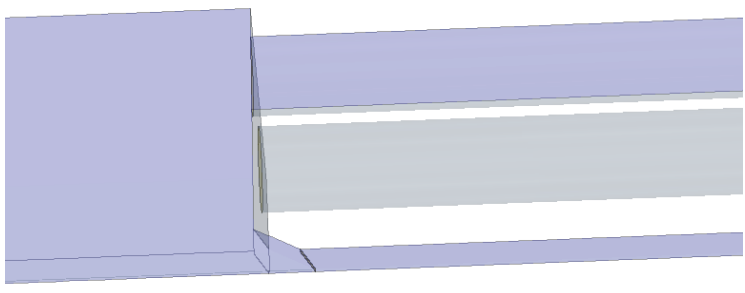

Fig. 7. Close-up view of upper plenum to vertical gap transition.

The upper plenum of the bypass apparatus is $178 \mathrm{~mm}$ long; the channels have $32 \mathrm{~mm}$ diameters; the first block is $1599 \mathrm{~mm}$ long; the second block is $326 \mathrm{~mm}$ long; the channels are located $28.4 \mathrm{~mm}$ from the top wall and are $65.6 \mathrm{~mm}$ apart; the span from the origin to the top of the block is $107 \mathrm{~mm}$; the distance from $\mathrm{X}$ $=0$ to the first corner at the top of the block is $115 \mathrm{~mm}$; the width of the angled edge to the right of said corner is $35 \mathrm{~mm}$; the bevel is $17 \mathrm{~mm}$ deep and $8.3 \mathrm{~mm}$ wide.

The inlet condition for the CFD models is set to a constant mass inflow for the one-sixth section. The mass inflow that can be pumped through the apparatus by the MIR facility pump is estimated to be $2.84 \mathrm{~kg} / \mathrm{sec}$ for the one-sixth sector. However, it was found that this flow rate resulted in laminar flow for all of the configurations. Therefore, a mass flow of $8.0 \mathrm{~kg} / \mathrm{sec}$ was also specified for two of the cases for comparison purposes. The three outlet conditions (for the full and half channels and the gap) are set to pressure outlet at $0 \mathrm{~Pa}$. The density and dynamic viscosity of the mineral oil are set to constant values of 831.1 $\mathrm{kg} / \mathrm{m}^{3}$ and $0.011685 \mathrm{~Pa}-\mathrm{sec}$, respectively.

The commercial code STARCCM+ (2010) is used for the computations. The flow in the upper plenum and the horizontal gap are assumed to be turbulent flow. The standard $\mathrm{k} \sim \varepsilon$ twolayer turbulence model using the all $\mathrm{y}^{+}$wall treatment is used. This turbulence model and wall treatment have been shown in companion studies to yield wall shear stress that is within 5\% of several published friction factor coefficients for $\mathrm{y}^{+}$values in the range 2 to 11 . The $\mathrm{y}^{+}$values for the nominal grids used herein is between 2 and 3. The turbulent inlet conditions are specified as turbulent kinetic energy $=0.01 \mathrm{~J} / \mathrm{kg}$ and dissipation rate $=0.1$ $\mathrm{J} / \mathrm{kg}$-sec.

STARCCM+ allows the suppression of turbulence in regions where the flow is expected to be laminar. For the present calculations when the gap flow is found to be laminar, the turbulence is suppressed in the region of the vertical gaps, not including the wider region where the bevels are located (at both ends of the first block and the front end of the lower block). Finally, as described above, it is intended that screens be positioned near the outlets of the gap and channels to increase the pressure drop such that the drop across the second block is about the same as across the first block. Inasmuch as no screen has yet been specified to do this, the screen sections are left as open flow regions in the present CFD models.

The segregated solver is used in STARCCM+ along with second-order differencing for the convection and diffusion terms. The solutions are iterated to residuals below $1.0 \times 10^{-4}$, for STARCCM+, which has been found to be sufficient for iterative convergence in previous studies (Johnson, 2009, 
Johnson et al, 2010) or until they do not converge further, as will be noted below. All walls are no-slip walls. No artificial diffusion is added.

The grids used in the present study contain a nominal 4.19 million cells. To determine if the mesh is sufficiently fine, a finer mesh was constructed by increasing the node count by 1.25 along the edges of the faces used to create the grid. The refined mesh contains 8.73 million cells. Results are obtained for the case of $2 \mathrm{~mm}$ vertical and $2 \mathrm{~mm}$ horizontal gaps for both the nominal and refined grid. Figure 8 plots axial pressure profiles through the center of the full channel and the center of the gap for the two cases. As can be seen, the profiles for the two cases are very close. In fact, the maximum variations in pressures for the channel and the gap are slightly less than $1 \%$, leading to the conclusion that the nominal grid is sufficiently fine.

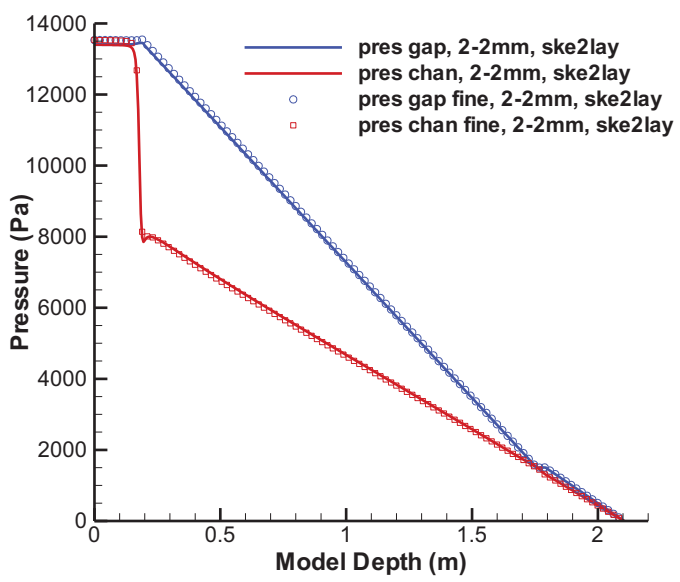

Fig. 8. Axial pressure profiles in the full channels and gaps.

\section{RESULTS AND DISCUSSION}

CFD calculations are made for six different cases for the bypass flow. These include the $2 \mathrm{~mm}$ vertical gap with $2 \mathrm{~mm}$ and $10 \mathrm{~mm}$ horizontal gaps and the $6 \mathrm{~mm}$ vertical gap for the same two horizontal gaps for inlet mass flow $2.84 \mathrm{~kg} / \mathrm{sec}$. Two additional simulations are made for the $6 \mathrm{~mm}$ and $10 \mathrm{~mm}$ vertical gap, both with $2 \mathrm{~mm}$ horizontal gap, for an inlet mass flow of 8.0 $\mathrm{kg} / \mathrm{sec}$. It was found that this flow rate yields transitional flow in the $6 \mathrm{~mm}$ vertical gap and turbulent flow in the $10 \mathrm{~mm}$ vertical gap configurations. Residuals for all cases are below $2 \times 10^{-4}$; except for the $6-2 \mathrm{~mm} / 2 / \mathrm{LF}$ case $(6 \mathrm{~mm}$ vertical $/ 2 \mathrm{~mm}$ horizontal gaps/low flow), whose residuals flattened out below $5 \times 10^{-4}$.

Table 1 summarizes the six cases. Quantities shown above the thick horizontal line are inputs; those below are outputs. The Reynolds numbers of the coolant tubes, based on tube diameter, and those of the gap, based on full gap width, are given. It is seen that flow in the coolant tubes is turbulent for all cases. For the gap flows, reference is made to Patel and Head (1969) who measured skin friction in pipes and channels (between parallel plates, not to be confused with the present coolant channels which are tubular). For a Reynolds number based on channel width ' $h$ ', they indicate that laminar flow occurs for $\operatorname{Re}_{h}<1300$, and fully turbulent flow for $\mathrm{Re}_{\mathrm{h}}>2800$; flow in between is transitional. It is seen that the gap flow for the lower mass flow rate cases is laminar. For the $6-2 \mathrm{~mm} / \mathrm{HF}$ (high flow) case, the gap flow is transitional. For the $10 / 2 \mathrm{~mm} / \mathrm{HF}$ case, the flow is in the turbulent zone. For these last two cases, the standard $k \sim \varepsilon$ turbulence model is used for entire flow field. While a transitional flow model is available in STARCCM+, it requires knowledge of turbulence levels at the inlet; these are not yet available. Hence, the flow computed in the gap for the 6$2 \mathrm{~mm} / 8.0 \mathrm{~kg} / \mathrm{sec}$ case is somewhat suspect.

Table 1. Summary of flow results for the six cases.

\begin{tabular}{|l|c|c|c|c|c|c|}
\hline $\begin{array}{l}\text { Vertical gap } \\
(\mathrm{mm})\end{array}$ & \multicolumn{2}{|c|}{2} & \multicolumn{3}{c|}{6} & 10 \\
\hline $\begin{array}{l}\text { Horizon. gap } \\
(\mathrm{mm})\end{array}$ & 2 & 10 & 2 & 10 & 2 & 2 \\
\hline $\begin{array}{l}\text { Total mass } \\
\text { flow (kg/s) }\end{array}$ & $\begin{array}{c}2.84 \\
(\mathrm{LF})\end{array}$ & $\begin{array}{c}2.84 \\
(\mathrm{LF})\end{array}$ & $\begin{array}{c}2.84 \\
(\mathrm{LF})\end{array}$ & $\begin{array}{c}2.84 \\
(\mathrm{LF})\end{array}$ & $\begin{array}{c}8.0 \\
(\mathrm{HF})\end{array}$ & $\begin{array}{c}8.0 \\
(\mathrm{HF})\end{array}$ \\
\hline $\begin{array}{l}\text { Re }{ }_{\text {chn }}\left(1^{\text {st }} \text { sec) }\right. \\
\text { flow regime }\end{array}$ & $\begin{array}{c}6387 \\
\text { turb. }\end{array}$ & $\begin{array}{c}6387 \\
\text { turb. }\end{array}$ & $\begin{array}{c}5440 \\
\text { turb. }\end{array}$ & $\begin{array}{c}5400 \\
\text { turb. }\end{array}$ & $\begin{array}{c}15024 \\
\text { turb. }\end{array}$ & $\begin{array}{c}12362 \\
\text { turb. }\end{array}$ \\
\hline $\begin{array}{l}\text { Re } \\
\text { gap }\left(1^{\text {st }} \text { sec) }\right.\end{array}$ & 31 & 32 & $\begin{array}{c}524 \\
\text { flow regime }\end{array}$ & $\begin{array}{c}543 \\
\text { lamin. }\end{array}$ & $\begin{array}{c}16 \mathrm{~min} . \\
\text { lamin. } \\
\text { lamin. }\end{array}$ & $\begin{array}{c}3192 \\
\text { trans. } \\
\text { turb. }\end{array}$ \\
\hline $\begin{array}{l}\text { Total press. } \\
\text { drop (Pa) }\end{array}$ & 13560 & 13720 & 10420 & 10600 & 64798 & 45334 \\
\hline $\begin{array}{l}\text { Gap fraction } \\
1^{\text {st }} \text { sec. }(\%)\end{array}$ & 0.97 & 0.97 & 15.6 & 16.2 & 17.3 & 31.9 \\
\hline $\begin{array}{l}\text { Gap fraction } \\
2^{\text {nd }} \text { sec. }(\%)\end{array}$ & 0.61 & 0.65 & 13.4 & 12.4 & 14.9 & 29.9 \\
\hline
\end{tabular}

The pressure drop is seen to be higher for the $2 \mathrm{~mm}$ vertical gap cases than for the $6 \mathrm{~mm}$ vertical gap cases for the lower mass flow. This is because the former present a smaller flow area, but with the same resistance to flow (that is, the same wall area) relative to the latter. For the lower mass flow, the flow in the $6 \mathrm{~mm}$ gaps is about 15 times that of the $2 \mathrm{~mm}$ gaps, though the flow area is only 3 times greater. This is a result of the increased flow area with no increase in flow resistance. This underscores the point that it is the flow resistance as well as the flow area that controls the relative flows in the coolant channels and bypass gaps.

It is seen that the flow fraction in the gaps in the $2^{\text {nd }}$ section is somewhat less than that in the $1^{\text {st }}$ sections in all cases, though the difference is less as the vertical gap width increases. This is probably due to the fact that the momentum of the flow in the upper plenum coming into the $1^{\text {st }}$ section gap is higher than is the momentum in the vicinity of the gap in between the two sections. However, this effect is diminished as the vertical gap width increases and the momentum in the gap also increases. Finally, note that the percent of mass flow fractions in the gaps for the $6-2 \mathrm{~mm}$ high mass flow case are about the same as for the $6-2 \mathrm{~mm}$ low mass flow case, even though one is turbulent and one is laminar. This is the case because, even though there is a variation in wall friction between laminar and turbulent flow, the difference between flow resistances in the coolant tubes versus the gap is far greater.

Figure 9 shows a contour plot for the streamwise velocity at a point $55 \mathrm{~mm}$ from the inlet for the $2-2 \mathrm{~mm} / \mathrm{LF}$ case. Note that the contour plots and profiles shown herein are smoothed by the 
CFD code. The maximum velocity magnitude is seen to be along a region parallel to the outer wall from where it drops to zero at the wall and drops slightly toward the three-gap junction. The 2$10 \mathrm{~mm} / \mathrm{LF}$ case is similar.

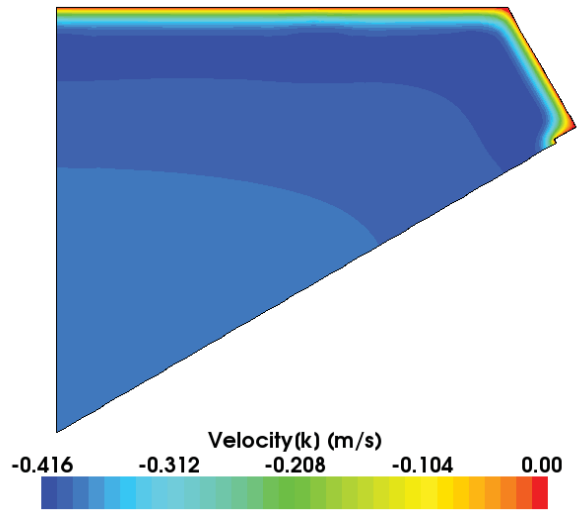

Fig. 9. Axial velocity contours at $55 \mathrm{~mm}$ for $2-2 \mathrm{~mm} / \mathrm{LF}$.

Figure 10 plots contours for the $6-2 \mathrm{~mm} / \mathrm{LF}$ case. The contours are similar to the $2-2 \mathrm{~mm} / \mathrm{LF}$ case except that the ridge of high velocity magnitude is concentrated near the upper right corner. Results for the other cases are similar.

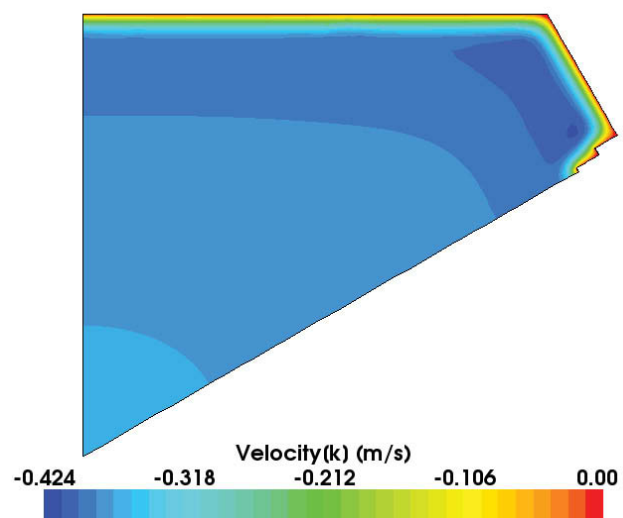

Fig. 10. Axial velocity contours at $55 \mathrm{~mm}$ for $6-2 \mathrm{~mm} / \mathrm{LF}$.

Figures 11, 12 and 13 show a side view of the velocity magnitude in the upper plenum and initial parts of the coolant channel and gap for the $2-2 \mathrm{~mm} / \mathrm{LF}$ case, the $6-2 \mathrm{~mm} / \mathrm{HF}$ case and the $10-2 \mathrm{~mm} / \mathrm{HF}$ case, respectively. The view plane cuts through the center of the full channel. As can be seen, the velocity changes little except near the wall at the top for at least half the length of the upper plenum. The increase in the gap width is obvious in the three figures. The ranges of the velocity magnitude are between the minimum and maximum for each case. Even though the first case is for low flow and the second two cases are for high flow, it is obvious that the velocity in the gap increases relative to the maximum velocity as the gap width increases. Also note that the flow in the channel for the wider $10-2 \mathrm{~mm} / \mathrm{HF}$ case is lower than for the $6-2 \mathrm{~mm} / \mathrm{HF}$ case because the gap flow is higher.

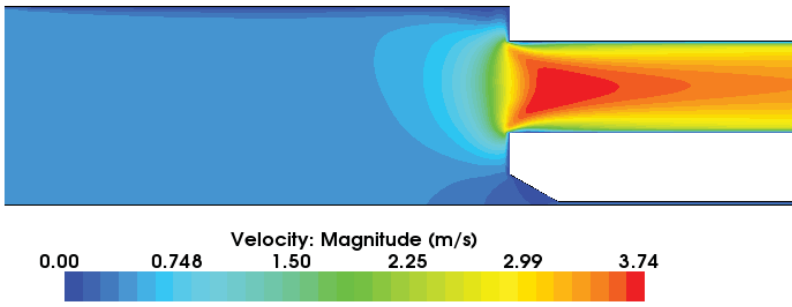

Fig. 11. Velocity magnitude in the upper plenum for $2-2 \mathrm{~mm} / \mathrm{LF}$.

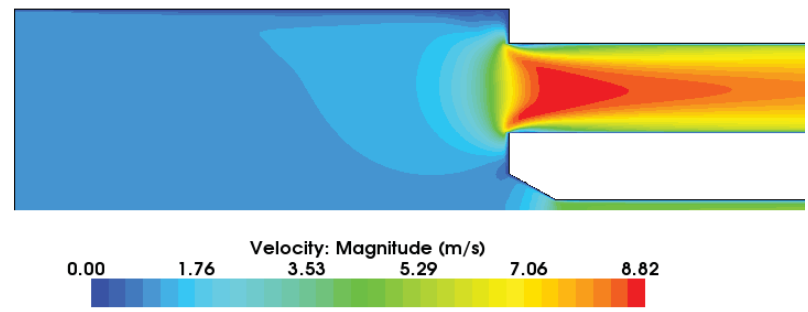

Fig. 12 Velocity magnitude in the upper plenum for $6-2 \mathrm{~mm} / \mathrm{HF}$.

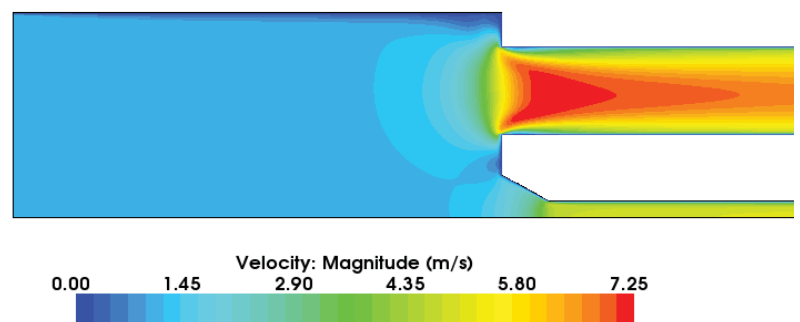

Fig. 13 Velocity magnitude in the upper plenum for $10-2 \mathrm{~mm} / \mathrm{HF}$.

Figures 14 and 15 provide contours of the turbulent to (molecular) viscosity ratio for $6-2 \mathrm{~mm} / \mathrm{LF}$ and $10-2 \mathrm{~mm} / \mathrm{HF}$ cases in the upper plenum and block entrance. While the turbulent quantities are constant at the inlet, there is large variation of the turbulent viscosity in the upper plenum. It remains to be seen what the actual levels will be in the data. Figure 15 shows the presence of turbulence in the gap.

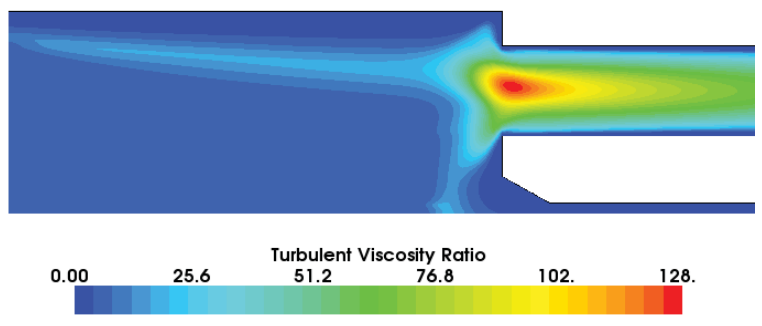

Fig. 14. Turbulent to molecular viscosity ratio for $6-2 \mathrm{~mm} / \mathrm{LF}$.

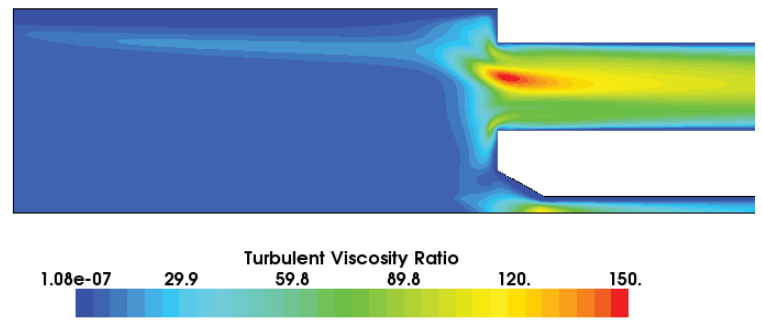

Fig. 15. Turbulent to molecular viscosity ratio for $10-2 \mathrm{~mm} / \mathrm{HF}$. 
An important aspect of the flow is the associated pressure drop. Figure 16 plots axial profiles of the pressure for the four low flow cases along the center of the gap, that is, centered between the right and left ends. The pressure drop for the two $2 \mathrm{~mm}$ vertical gap cases is much higher than for the $6 \mathrm{~mm}$ cases. This is expected because the narrower gaps present greater resistance. The width of the horizontal gap appears to make little difference on the overall pressure drop. There is, however, a slight bump in pressure at the horizontal gap, which starts at $\mathrm{Z}=$ $1.776 \mathrm{~m}$, for the $6-2$ and $6-10 \mathrm{~mm}$ cases.

Figure 17 plots the axial pressure profiles for the four low flow cases along the centerline of the full channel. The pressure drop decreases in the channels as the vertical gap width increases; this is because there is a lower flow rate in the channels for the $6 \mathrm{~mm}$ vertical gap cases. Figure 18 gives axial pressure profiles for the two high flow cases for gaps and channels. The difference in pressure profiles decreases as the flow resistances are closer between gap and channel, as seen. The pressure needed to drive the $8.0 \mathrm{~kg} / \mathrm{sec}$ is much higher than for the lower flow rates.

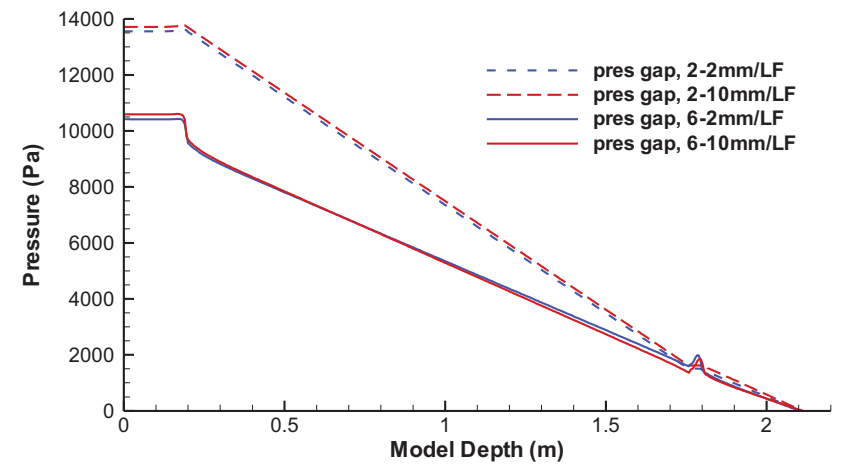

Fig. 16. Axial pressure in the gap for the low flow cases.

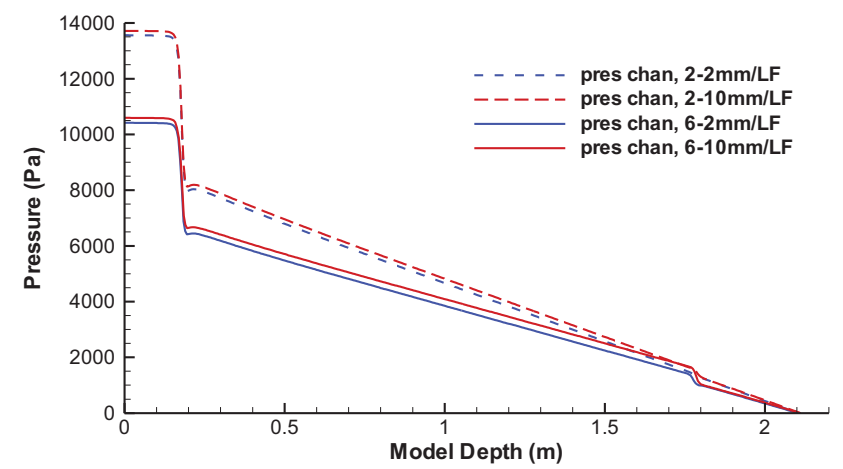

Fig. 17. Axial pressure in the full channel for low flow cases.

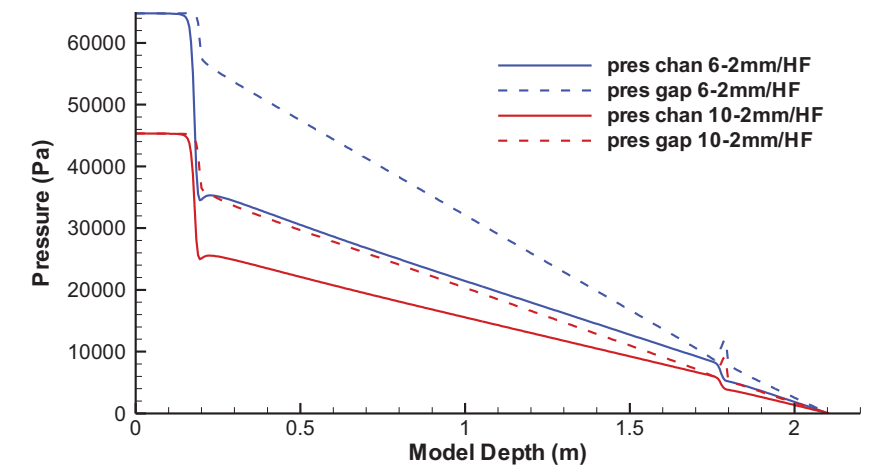

Fig. 18. Axial pressure profiles for the high flow cases.
Radial velocity profiles are plotted at four axial locations in the full channel in the first block, at 0D, 25D, 45D and 48D (diameters) from the channel entrance in Figure 19 for the 2$2 \mathrm{~mm} / \mathrm{LF}$ case. Note that the channel is $49.95 \mathrm{D}$ long in the first block. As can be seen, the turbulent flow appears to be fully developed by 25D, as it doesn't change beyond this location. Figure 20 plots the similar profiles for the $6-2 \mathrm{~mm} / \mathrm{LF}$ case. The profiles are similar as for the previous case, except that there is a lower bulk velocity for this case. Figure 21 plots the radial profiles of the mean axial velocity for the two high flow cases, $6-2 \mathrm{~mm} / \mathrm{HF}$ and $10-2 \mathrm{~mm} / \mathrm{HF}$. The overall velocity is much higher than for the low flow cases. The velocity is higher for the $6 \mathrm{~mm}$ case because more flow goes into the bypass gap for the $10 \mathrm{~mm}$ case.

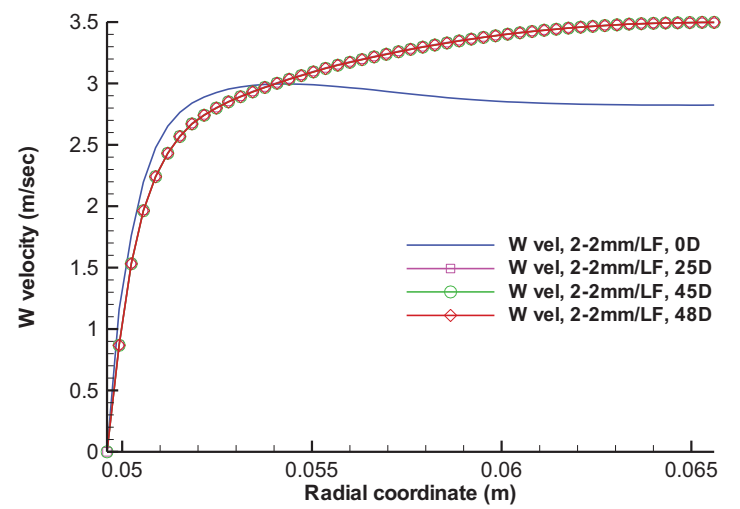

Fig. 19. Radial velocity profiles in the channel for $2-2 \mathrm{~mm} / \mathrm{LF}$.

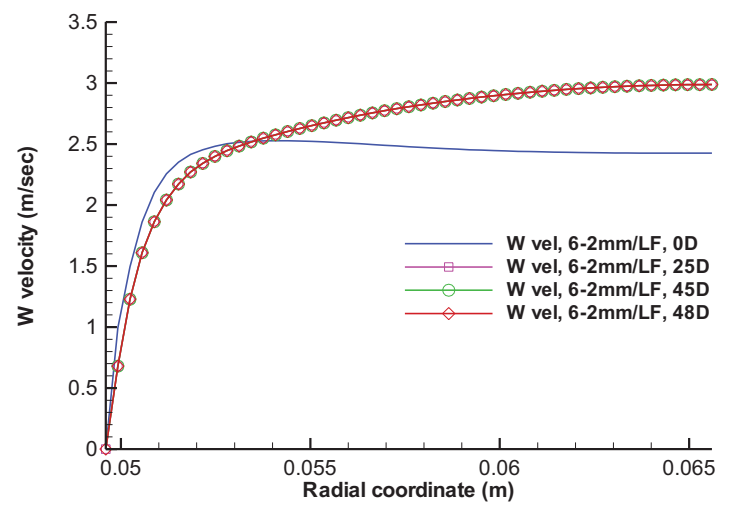

Fig. 20. Radial velocity profiles in the channel for $6-2 \mathrm{~mm} / \mathrm{LF}$.

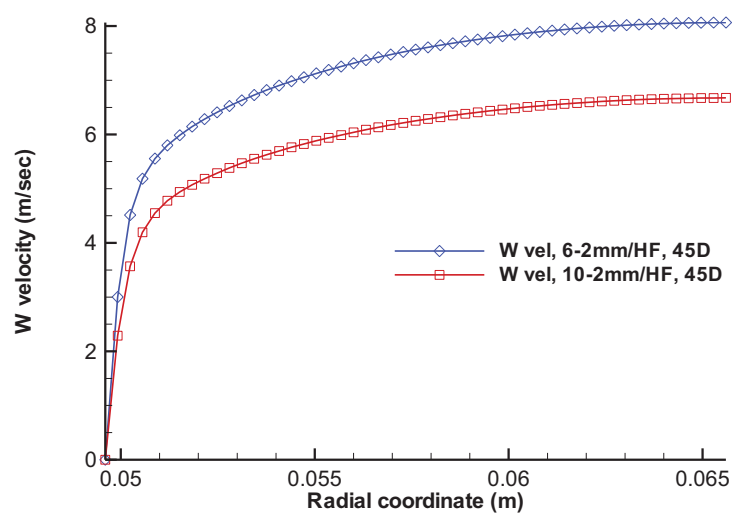

Fig. 21. Radial velocity in the channel for the two HF cases. 
Velocity profiles are provided by Figures 22 and 23 for the flow in the gaps for the LF cases. The profiles are taken at the same depth as for the 45D channel location, which is over 700 gap widths for the $2 \mathrm{~mm}$ vertical gap cases. Turbulence has been suppressed for the gap flows in the LF cases, making it laminar. The computed profiles are each compared to the theoretical profiles computed from the analytical solution for fully developed laminar flow in a channel. The analytical profiles are based on the maximum flow velocity which comes from the CFD calculations. The flow profiles conform very closely to the analytical laminar solutions. Figure 24 shows the gap profiles at the same axial location for the two HF cases; the flows are modeled as turbulent.

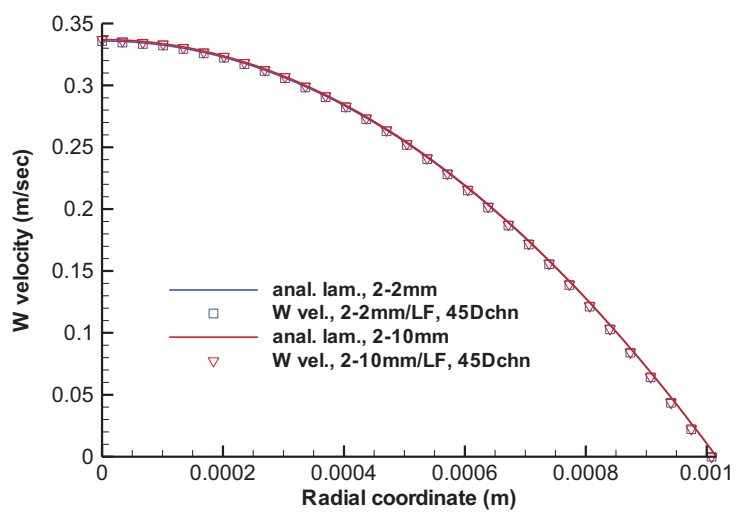

Fig. 22. Radial velocity profiles for the $2 \mathrm{~mm}$ vertical gap cases compared to the analytical solutions.

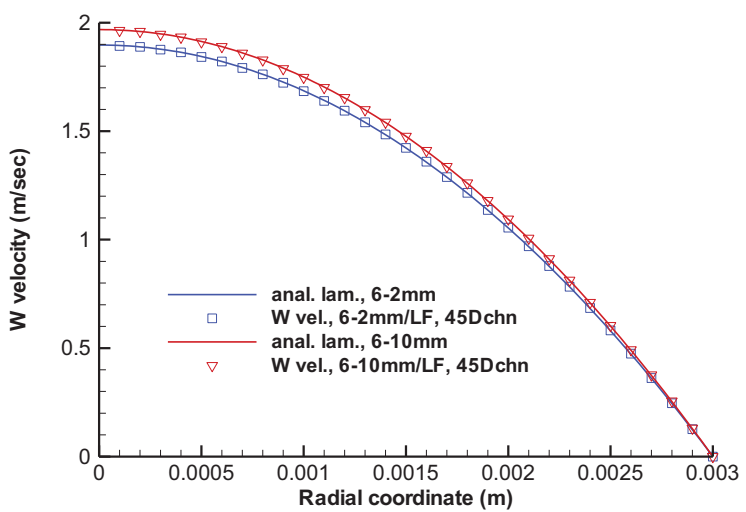

Fig. 23. Radial velocity profiles for the $6 \mathrm{~mm}$ vertical gap cases compared to the analytical solutions.

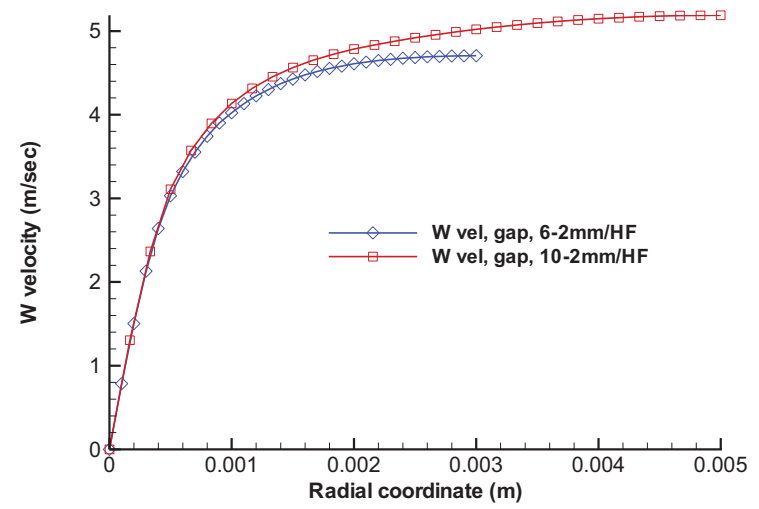

Fig. 24. Radial velocity profiles for the HF cases in the gap.
An interesting feature of the bypass flow is the junction of the three vertical gaps at the center of the apparatus (Fig. 2). The junction is a region of lower flow resistance. Figures 25, 26 and 27 show contour plots of the gap junction for the 2, 6 and 10 $\mathrm{mm}$ vertical gaps in the first block. The velocity is a maximum at the junction centers. However, the region of higher velocity is small making this effect insignificant.

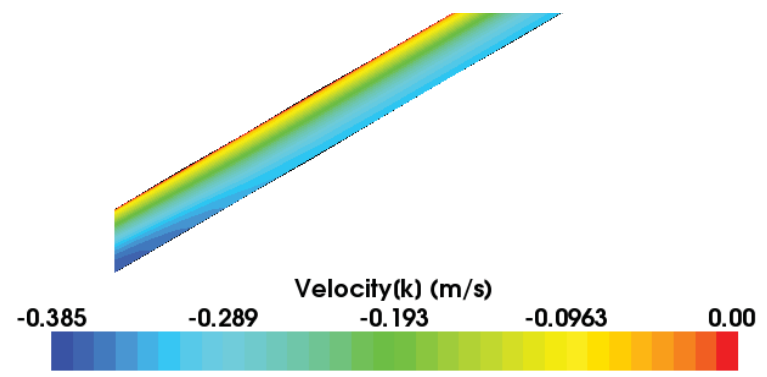

Fig. 25. Axial velocity at gap junction for $2-10 \mathrm{~mm} / \mathrm{LF}$.

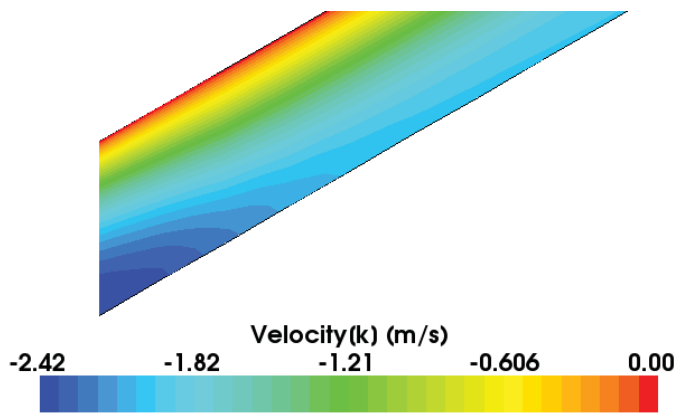

Fig. 26. Axial velocity at the gap junction for $6-10 \mathrm{~mm} / \mathrm{LF}$.

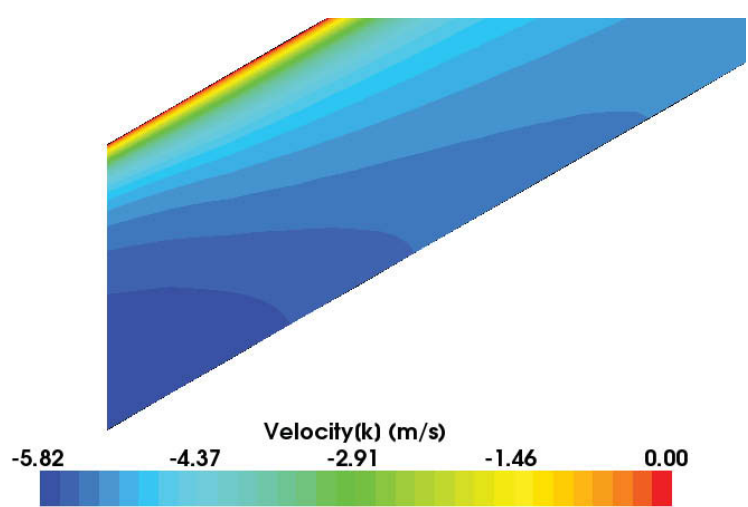

Fig. 27. Axial velocity at the gap junction for $10-2 \mathrm{~mm} / \mathrm{HF}$.

Figure 28 plots the vertical velocity for cases $2-10 \mathrm{~mm} / \mathrm{LF}, 6-$ $10 \mathrm{~mm} / \mathrm{LF}$ and $10-2 \mathrm{~mm} / \mathrm{HF}$ cases from the center of the junctions along the plane of symmetry at axial location 45D. The flow velocity is significantly higher in the high flow $10 \mathrm{~mm}$ case than the other two cases as expected. The extent of the velocity increase along the plane of symmetry is greater the larger the gap. Nevertheless, the extent of the region of increased velocity is small relative to the whole lateral gap span. Note that the distance along the gap in Fig. 28 extends from the junction center to the midpoint of the span of the gap in the CFD model; the gap span of the model is only about one-third of the total gap span. (See Fig. 2.) 


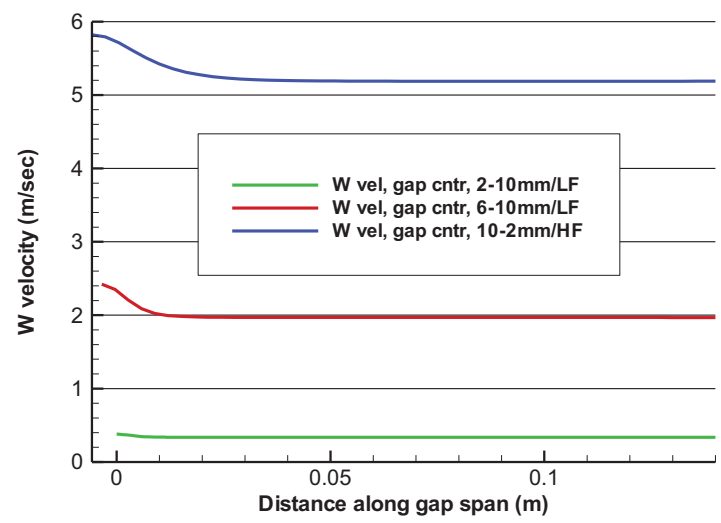

Fig. 28. Velocity for gap span center for $2-10 \mathrm{~mm}, 6-10 \mathrm{~mm}$.

It is interesting to examine the pressure distribution in the horizontal gap between the two blocks. Figures 29-31 plot pressure contours in the horizontal gaps at planes half-way between the two blocks for three cases. Figures 29-30 show pressure for 2 and $10 \mathrm{~mm}$ vertical gaps, both with $2 \mathrm{~mm}$ horizontal gaps. An increase in pressure is seen to occur in each case from the coolant channels towards vertical gap along the diagonal edge. The lateral pressure gradient has mostly to do with the flow resistance present due to the narrowness of the horizontal gap. The one $10 \mathrm{~mm}$ horizontal gap case shown, Fig. 31 , for the $2-10 \mathrm{~mm} / \mathrm{LF}$ case, shows no lateral pressure gradient except near the channels where it shows a series of peaks and valleys, which are related to a vortex ring in the gap as can be seen in Fig. 32.

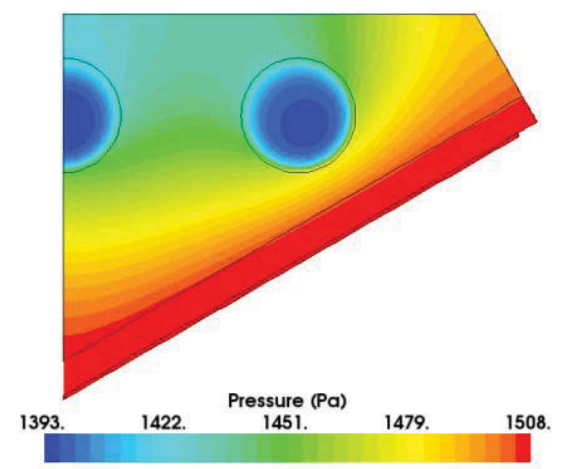

Fig. 29. Pressure in the horizontal gap for $2-2 \mathrm{~mm} / \mathrm{LF}$.

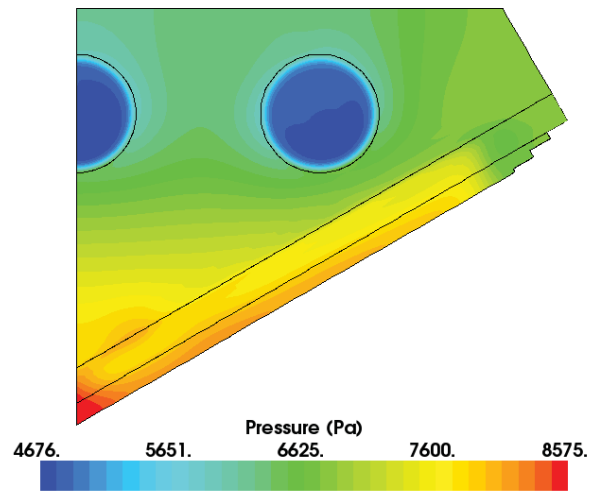

Fig. 30. Pressure in the horizontal gap for $10-2 \mathrm{~mm} / \mathrm{HF}$.

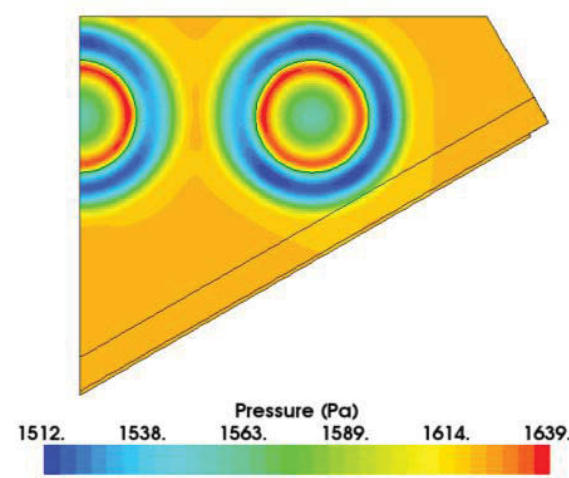

Fig. 31. Pressure in the horizontal gap for $2-10 \mathrm{~mm} / \mathrm{LF}$.

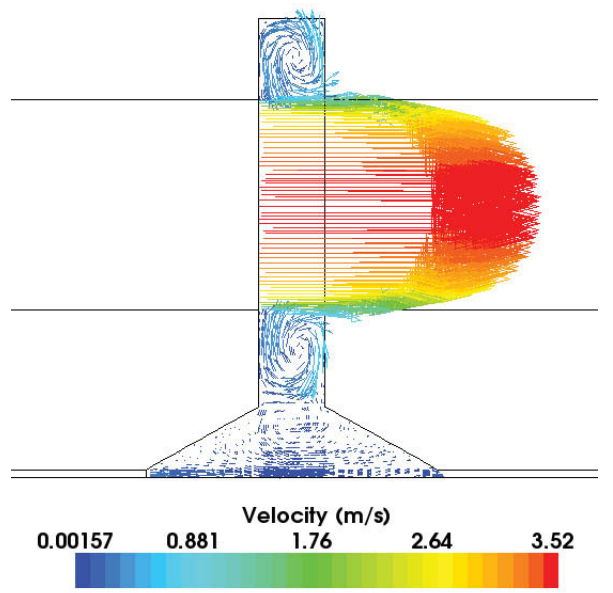

Fig. 32. Velocity vectors in the horizontal gap for $2-10 \mathrm{~mm} / \mathrm{LF}$.

Figures 33-35 provide contour plots of the velocity magnitude at the half-way point in the horizontal gap for 2$2 \mathrm{~mm} / \mathrm{LF}, 6-2 \mathrm{~mm} / \mathrm{LF}$ and $10-2 \mathrm{~mm} / \mathrm{HF}$ cases. Results for the cases with wider horizontal gaps are similar to those for the narrower gaps. While the velocity magnitude for the channels is the greatest, it can be seen that the velocity in the 6 and $10 \mathrm{~mm}$ gaps in Figs. 34, 35 is relatively greater than in the $2 \mathrm{~mm}$ gap in Fig. 33. This emphasizes the fact that the resistance to flow has a primary influence in the bypass flow, not just the size of the flow opening. In other words, the amount of wall (resistance) per unit of flow area is a significant factor in determining the flow rate of the bypass (and all) flow.

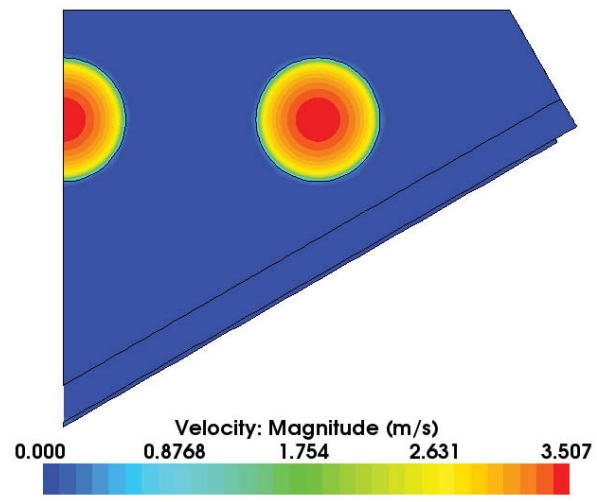

Fig. 33. Velocity magnitude in horizontal gap for $2-2 \mathrm{~mm} / \mathrm{LF}$. 


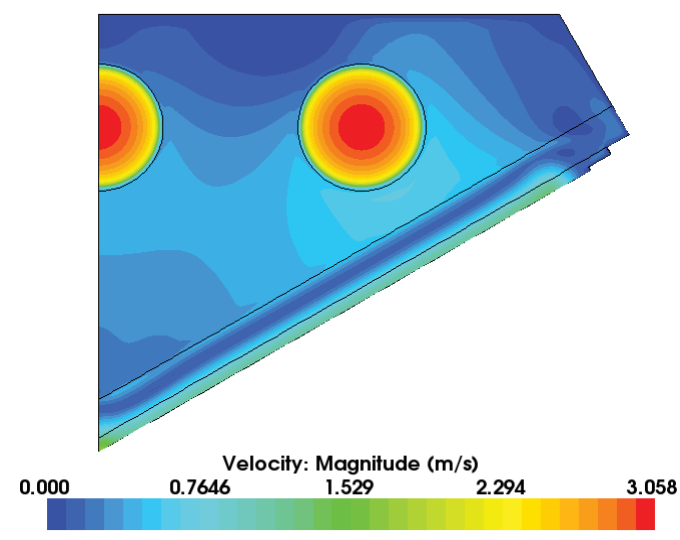

Fig. 34. Velocity magnitude in horizontal gap for $6-2 \mathrm{~mm} / \mathrm{LF}$.

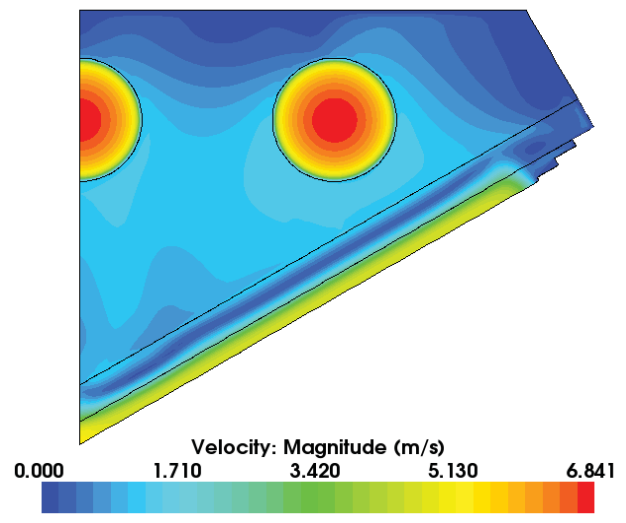

Fig. 35. Velocity magnitude in horizontal gap for $10-2 \mathrm{~mm} / \mathrm{HF}$.

In summary, quantitative results have been provided to describe the isothermal flow in six configurations of the MIR bypass flow apparatus. Velocity and pressure profiles are presented that may be compared to eventual experimental data. Of course, the inlet flow conditions may be somewhat different in the actual experiments.

\section{CONCLUSIONS}

Flow in a bypass apparatus that includes both coolant channels and bypass flow gaps, representative of a graphite block in a prismatic HTGR, has been modeled using CFD. Vertical gaps that occur laterally between blocks vary between 2, 6 and $10 \mathrm{~mm}$. Horizontal gaps between blocks vary between 2 and $10 \mathrm{~mm}$. Inasmuch as the scale is a factor of 2 greater than actual scale, these gaps are twice those that would occur in the reactor. Flow in the gaps is laminar for the four low flow cases and transitional and turbulent for the high flow cases. The coolant channel flow is fully turbulent in all cases. It was also found that while the velocity in the center of the junction of three converging gaps is higher because of lower resistance, the effect is rather insignificant. It was found that the flow in the vertical gap increases nonlinearly with an increase in gap width, that is, the gap flow increases by a factor of at least 15 while the gap flow area only increases by a factor of 3 . This points to the fact that the flow is a factor of both flow area and flow resistance (wall friction).

\section{ACKNOWLEDGMENTS}

This manuscript has been authored by Battelle Energy Alliance, LLC under Contract No. DE-AC07-05ID14517 with the U.S. Department of Energy.

\section{REFERENCES}

FLUENT, 2010, ANSYS, Inc., 275 Technology Drive Canonsburg, PA 15317.

GA Technologies, Inc., 1992, Preliminary Safety Information Document for the Standard MHTGR, document HTGR-86-024, rev. 13.

Johnson, R. W., and H. Sato, 2010, Bypass Flow Computations using a One-Twelfth Symmetric Sector for Normal Operation in a 350 MWth Prismatic VHTR, HTR2010, Prague, Oct. 18-20, paper 152.

Johnson, R. W, and R. R., Schultz, 2004, Bounding Estimate for the 'Hot' Channel Coolant Temperature and Preliminary Calculation of Mixing in the Lower Plenum for the NGNP Point Design Using CFD, INEEL/EXT-04-02570, Rev. 1.

Johnson, R. W., 2009, "Examination of a Proposed Validation Data Set Using CFD Calculations," paper FEDSM2009-78317, Proceedings of FEDSM2009 ASME 2009 Fluids Engineering Summer Meeting August 2 - 5, Vail, Colorado.

Johnson, R. W., H. M. McIlroy, R. C. Johnson and D. P. Christensen, 2010, "Undesirable Flow Behavior in a Proposed Validation Data Set," Paper ICONE18-29474, Proceedings of the 18th International Conference on Nuclear Engineering (ICONE18), May 17-21, Xi'an, China.

MacDonald, P., J. Sterbentz, R. Sant, P. Bayless, R. Schultz, H. Gougar, R. Moore, A. Ougouag, W. Terry, 2003, NGNP Preliminary Point Design Results of the Initial Neutronics and Thermal-Hydraulic Assessments, INEEL/EXT-03-00870.

Patel, V. C. and Head, M. R., 1969, Some observations on skin friction and velocity profiles in fully developed pipe and channel flows, J. Fluid Mech., 38(1), 181-201.

Sato, H., R. W. Johnson, R. R. and Schultz, 2010, Computational Fluid Dynamic Analysis of Core By-pass Flow Phenomena in a Prismatic VHTR, Annals of Nuclear Energy, 37, 1172-1185.

STAR-CCM+, version 5.02.009, 2010, CD-adapco, 60 Broadhollow Road, Melville, NY 11747.

Tak, N., M. Kim, W. Lee, 2008, Numerical investigation of a heat transfer within the prismatic fuel assembly of a very high temperature reactor, Annals of Nuclear Energy, 35, 1892-1899. 